\title{
AGENESIAS E CAVOS DO SEPTO PELÚCIDO
}

\author{
Carlos R. A. Vieira * \\ LUIS MARQUES-ASSIS ** \\ Milberto ScAFF** \\ Gilberto Machado de Almeida *** \\ Nélio Garcia dE Barros ****
}

O septo pelúcido, delgada parede que separa os dois ventrículos laterais, consiste de duas tênues lâminas verticais que, durante a embriogênese, se distenderam, preenchendo o intervalo triangular entre o fómice e o corpo caloso. Essas duas lâminas podem se encontrar fundidas, separadas por um espaço virtual ou delimitando uma grande cavidade, denominada quinto ventriculo ou cavo do septo pelúcido. Lowman e col. ${ }^{3}$ mencionam variações na morfologia do septo pelúcido que, às vêzes, pode estar ausente; quando presente está usualmente intacto embora, ocasionalmente, com fenestrações que permitem comunicação direta com os ventrículos laterais.

Turner (1878), citado por St. John e Reeves ${ }^{7}$, foi o primeiro a observar a ausência anatômica do septo pelúcido. Sfintzescu e Mihailescu citam um caso registrado por Forster, em 1933, no qual o defeito septal foi evidenciado pela pneumencefalografia. A incidência de agenesia do septo pelúcido (SP) é variável. Segundo Madonick e col. ${ }^{4}$, Davidoff e Dyke (1935) encontraram um caso entre 2.500 estudados pela pneumencefalografia. Vinken e Strackee-Kuijer (1957) diagnosticaram agenesia do SP duas vêzes, numa série de 1.500 casos $^{4}$. Thieffry e col. ${ }^{8}$ (1958) observaram, entre 1.349 pneumencefalografias, 12 com sinais de agenesia do SP. St John e Reeves ${ }^{7}$ (1957) observaram a anomalia em embrião de três meses e em homem de 74 anos de idade. Os mesmos autores asseveram que a agenesia do SP, sem evidência de hidrocefalia ou outra anormalidade encefálica associada, constitui exceção.

As características pneumencefalográficas da ausência do SP foram descritas em 1935 por Dyke e Davidoff ${ }^{1}$ : "Nas posições antero-posterior e póstero-anterior os ventrículos laterais aparecem confluindo medialmente. A costumeira sombra linear vertical, produzida pelo septo pelúcido está ausente. $\mathrm{Na}$ linha média, ventralmente, há uma projeção dos ventrículos semelhante a um mamilo".

Clínica Neurológica (Prof. Horácio M. Canelas) do Departamento de Neuropsiquiatria da Faculdade de Medicina da Universidade de São Paulo: * Médico estagiário; ** Médico assistente; *** Docente livre; **** Radiologista. 
Os têrmos cisto e cavo do SP têm sido usados indiferentemente. Alguns autores diferenciam cisto como dilatação desta estrutura, isolada dos ventrículos laterais e cavo como dilatação comunicante. ${ }^{4}$

Schwidde ${ }^{6}$ (1952) encontrou cistos do SP em 20,34\% de 1.032 necrópsias. Em 1.500 pneumencefalografias, Zellweger e von Muralt ${ }^{9}$ (1952) encontraram dois exemplos de cavo do SP. Tenchini, citado por Hughes e col. ${ }^{2}$ (1955), postula que cisto e cavo do SP ocorrem em $4 \%$ de homens e $9 \%$ de mulheres. Thieffry e col. ${ }^{8}$ (1958) encontraram cistos do SP em 5 e cavo do SP em 6 casos entre 1.349 pneumencefalografias realizadas em lactentes. Schunk ${ }^{5}$ (1963) encontrou, em 307 encéfalos de pacientes com algum tipo de distúrbio neurológico que os levou à morte, $60 \%$ com cisto do SP. Cavo do SP é comumente encontrado em encéfalos de crianças, freqüentemente obliterando-se na idade adulta ${ }^{4}$.

Nosso propósito é apresentar 4 casos de agenesia e um de cavo do septo pelúcido, dada a raridade destas entidades.

\section{O B S E R V A C O E S}

CASo 1 - P.E.J., sexo masculino, 7 meses de idade, branco, natural de São Paulo (RG.HC. 608495). Em 9 de janeiro de 1961 foi trazido ao Hospital por apresentar anormalidade no crânio, desde o nascimento. Nasceu de parto a têrmo, domiciliar, sem sinais de anóxia. Sorriu com dois meses, segurou objetos com 4 meses, sentou com 6 meses. Segundo filho de pais não consanguineos, sadios. Mãe com 34 anos. Exame neurológico - Normal para a idade exceto no que concerne ao exame do crânio: perimetro craniano (PC) $38 \mathrm{~cm}$, dlâmetro anteroposterior (DAP) $13 \mathrm{~cm}$, diâmetro bitemporal (DT) $11,5 \mathrm{~cm}$. Chama a atencão o alongamento do crânio para cima (turricefalia), sendo o DAP anormalmente pequeno. A inspecção, saliência na região frontal mediana, correspondente à sutura metópica e extremidade anterior da sagital. Fontanela bregmática completamente fechada. Lambda aberto. Craniograma: sinais de soldadura precoce das suturas coronária, metópica e porção mais ventral da sagital; ausência de sinais de hipertensão intracraniana. Teste de Gesell: idade cronológica de 24 semanas; paciente situado no setor motor ao nivel de 12 semanas e nos setores adaptativo, linguagem e pessoal-social ao nível de 16 semanas; retardo global intenso, não uniforme, predominando no setor motor. Pneumencefalografia (fig. 1): discreta dilatação do sistema ventricular; acentuação dos sulcos corticais das regiões frontoparietais; não é visivel a 1magem do septo pelúcido.

Cirurgia - Craniectomia em 31-1-61 realizada para refazer as suturas coronária, sagital e metópica. Os bordos ósseos foram protegidos com lâmina de polietileno. Pós-operatório sem anormalidades. Evolução - O teste de Gesell, realizado em acompanhamento ambulatorial, um mês após a cirurgia, revelou situar-se no setor motor ao nivel de 28 semanas; no setor pessoal-social entre 28 e 32 semanas; retardo intenso global mais acentuado no setor da motricidade e adaptativo.

Reinternado em 23-5-61, com diagnóstico de craniostenose recidivada. A mãe do paciente nāo constatou melhora no desenvolvimento da criança após a cirurgia. śxame neurológico - Criança lúcida, contactuando pela visão, audição e mímica; 1rritadiça. PC $42 \mathrm{~cm}$, DAP $13,5 \mathrm{~cm}$, DT $12 \mathrm{~cm}$. Abóbada craniana nāo apresenta sua curvatura normal, com angulacão na união das regiôes fronto-parietais e parietooccipitais. $\mathrm{Na}$ região frontal há uma saliência óssea na linha média. A regiāo supra-orbitária, na sua porção lateral, acha-se deprimida havendo saliência da arcada. Região occipital achatada. Falhas ósseas na regiāo lambdóidea e frontal esquerda. Nenhum sinal neurológico focal. Craniograma: sinais de extensa craniectomia fron- 


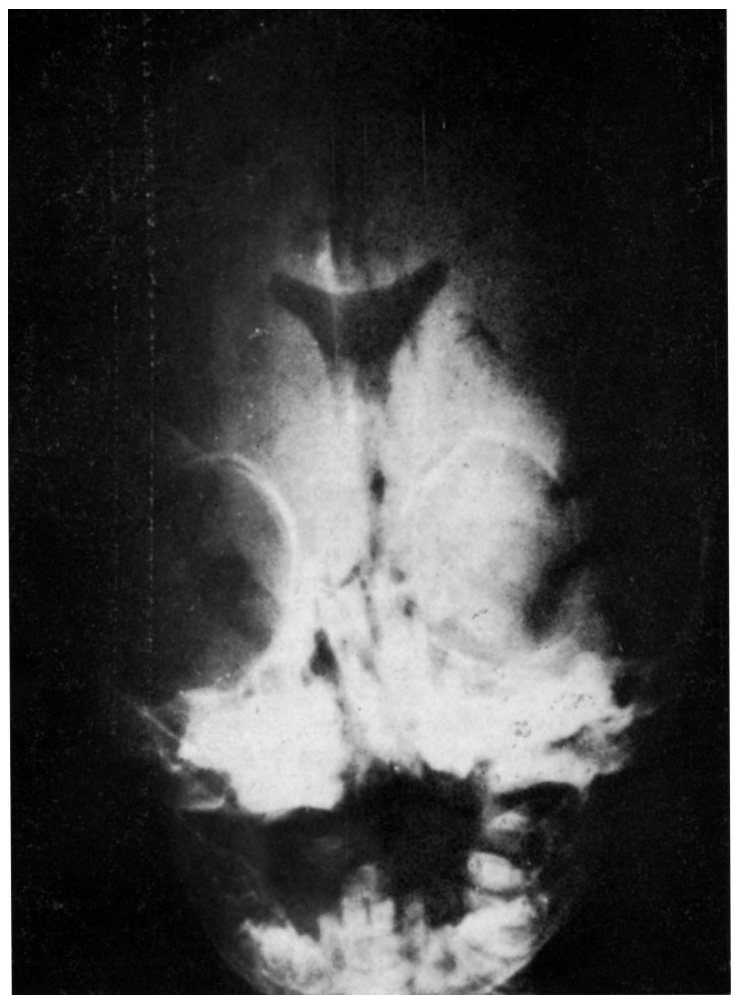

Fig. 1 - Caso 1, P.E.J., pneumencefalografia. Discreta dilatação do sistema ventricular. Não é visivel a imagem do septo pelúcido.

toparietal ao longo das suturas coronária e sagital; existem pontes de osso neoformado unindo os bordos ósseos; falha óssea em cruz com diâmetro ao redor de 3 a $4 \mathrm{~cm}$.

O paciente foi reoperado, em 31-5-61, sendo confirmada a existência de pontes ósseas por cima e por baixo das lâminas de polietileno. A evolução foi satisfatória e mais dois testes de Gesell evidenciaram melhora do desenvolvimento psicomotor persistindo discreto retardo.

Caso 2 - L.C.B., sexo masculino, 23 meses de idade, branco, natural de São Paulo (RG.HC 626427). Primeira consulta em 15-6-61. Nascido em 27-7-59, de parto a têrmo, hospitalar, normal. Aos 7 meses de idade, a mãe notou que a criança ainda não sustentava a cabeça. Nessa ocasião o exame radiográfico do crânio mostrou sinais sugestivos de hipertensāo intracraniana. Ao exame, constatou-se retardo no desenvolvimento neuropsicomotor, crânio pequeno, porém, harmônico: PC $48 \mathrm{~cm}$. Pneumencefalografia: acentuação dos sulcos corticais especialmente nas regiões frontais; no sistema ventricular o ar não progrediu além do quarto ventriculo.

Angıografia pela carótida esquerda: trajeto anômalo da artéria cerebral anterior, sugerindo a possibilidade de agenesia do lobo frontal. Pneumoventriculografia: a porçāo rostral do sistema ventricular é representada por cavidade única resultante da união dos côrnos frontais e da porção rostral do terceiro ventriculo. Os côrnos occipitais e temporais estão separados. Quadro de agenesia do septo pelúcido. 
Caso 3 - L.C., sexo masculino, 16 anos de idade, branco, solteiro, procedente de Umuarama, Paraná (RG.HC. 779258). Primeira consulta em 27-8-65. A mãe informa que quando o paciente leva susto, ou é surpreendido por ruidos mesmo pouco intensos, caí repentinamente e, após pequeno periodo apresenta convulsāo tônico-clônica. Quase diàriamente, ao conciliar o sono, tem abalos musculares que, muitas vêzes, são seguidos por crises completas. As crises tiveram início há um ano, após queda com traumatismo craniano, sem perda de consciência. Antecedentes familiares - tio materno epiléptico. Antecedentes pessoais - parto a têrmo, domiciliar, normal. Andou com dois anos. Falou as primeiras palavras aos três anos. Grande dificuldade nos estudos, não tendo ultrapassado o segundo ano primário. Ao exame constata-se apenas rebaixamento intelectual. Craniograma normal. Liquido cefalorraqueano normal. Reaçōes para lues e cisticercose no sangue e líquor, negativas. Eletrencefalograma: discreta anormalidade paroxistica na região centroparietal direita (grupos de ondas de seis a dez ciclos por segundo, de voltagem mais elevada); não foi constatada anormalidade à fotostimulação. O paciente recebeu medicação anticomicial (associação de barbitúrico e hidantoinato) ficando em contrôle ambulatorial. Seis meses após foi associada primidona devido ao aumento da freqüência das crises. Pneumencefalografia: fusão das imagens correspondentes aos corpos dos ventriculos laterais, resultando imagem simétrica de ângulos superolaterais arredondados, faltando a imagem do septo interventricular; retenção de grande volume de ar na fossa infratentorial, disposto em forma de crescente, de concavidade voltada para cima e para frente; sulcos cerebrais sem particularidades; quadro de agenesia do septo pelúcido e hipoplasia cerebelar.

Caso 4 - A.R., sexo feminino, 18 anos de idade, branca, solteira, procedente de Campinas, São Paulo (RG.HC. 586999). Primeira consulta em 24-5-60. Há 6 anos passou a apresentar crises convulsivas noturnas tônico-clônicas, com aura visual. Frequiência de três a quatro crises por mês. Antecedentes familiares - irmão epiléptico. Antecedentes pessoaís - parto a têrmo, domiciliar, normal. Andou com 18 meses. Falou com 12 meses. Ao exame apenas rebaixamento psiquico. Liquido cefalorraqueano normal. Eletrencefalograma: foco epileptógeno na regiāo temporal esquerda constituído por numerosas ondas sharp de voltagem elevada. Medicada com hidantoinatos, barbitúrico, a paciente mantém-se em contrôle ambulatorial sempre mostrando irregularidade no uso da medicação, tendo crises esporádicas até fevereiro de 1969 quando passou a apresentar fraqueza geral, não podendo deambular sem auxilio, com maior rebaixamento mental e disartia. Pneumencefalografia (outubro de 1969): ventriculos laterais de situação normal e volume aumentado; ausência da imagem do septo pelúcido; alargamento dos sulcos cerebrais; quadro de atrofia cerebral difusa e agenesia do septo pelúcido.

Caso 5 - I.Z., sexo masculino, 50 anos de idade, branco, casado, procedente đe Săo Paulo (RG.HC. 204558). Primeira consulta em 2-1-51. Há um mês, aproximadamente, apresentou duas crises convulsivas generalizadas. No dia seguinte teve novas crises, começando pela face e propagando-se para o hemicorpo direito. Exame neurológico: hemiparesia direita incompleta desproporcionada mais acentuada no membro inferior. Reflexos profundos vivos no membro inferior direito. Craniograma normal. Eletrencefalograma normal. Liquido cefalorraqueano: discreta hiperproteinorraquia com reaçoes coloidais do tipo parenquimatoso. A pneumencefalo. grafia mostrou alargamento dos sulcos da convexidade cerebral, difusamente, um pouco mais acentuado nas regiōes parietais; presença de cavo do septo pelúcido (fig. 2).

\section{O M E N TA R I O S}

Entre os nossos 4 pacientes com agenesia do septo pelúcido, foram evidenciadas outras anomalias associadas em três (craniostenose no caso 1 , agenesia do lobo frontal no caso 2 , hipoplasia do cerebelo no caso 3 ). Crises convulsivas estavam presentes em dois (casos 3 e 4) e retardo mental em 


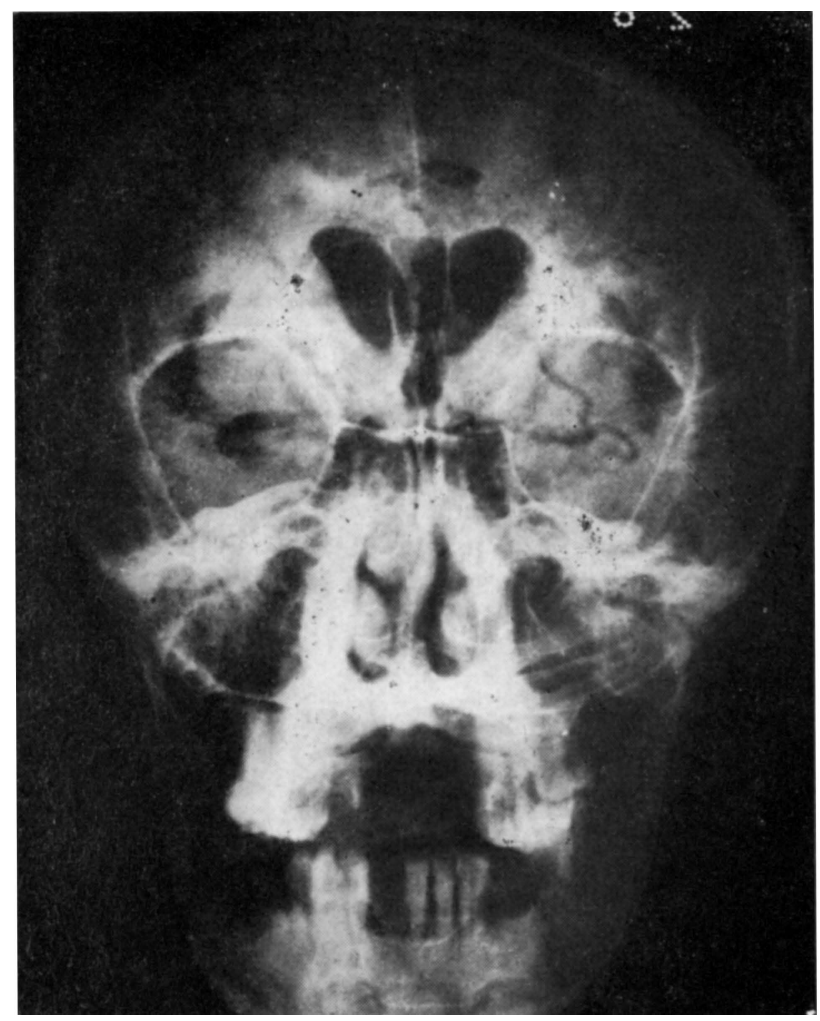

Fig. 2 - Caso 5, I.Z., pneumencefalografia. Nota-se aspecto típico do cavo do septo pelúcido.

três ( $\operatorname{casos} 1,2$ e 4). Em todos foi evidenciada agenesia do septo pelúcido por exame neurorradiológico. O paciente com cavo do septo pelúcido teve crises convulsivas focais com generalização ulterior.

Ésses achados concordam com aqueles encontrados na revisão de 74 casos de agenesia do SP feita por Madonick e col. ${ }^{4}$. Estes autores encontraram alterações mentais em 17 casos, deficits motores em 9, alterações visuais em 6, ataxia em 5, alterações da fala em dois, deficit sensitivo em um, movimentos anormais em um, crises convulsivas em 23, hidrocefalia grave em 10 e moderada em 10 casos. É freqüente a associação com anomalias como spina bífida, porencefalia, esclerose tuberosa, siringomielia, amaurose bilateral, enoftalmo, microcefalia e agnesia dos fórnices ou dos bulbos olfatórios, agenesia do corpo caloso, crânio lacunar, displasia do tracto óptico, agenesia dos tratos olfatórios e agiria. As características clínicas observadas entre 91 casos com cisto ou cavo do septo pelúcido são semelhantes ${ }^{4}$ : alterações mentais em 35 casos, motoras em 25 , cefaléia em 18, dificuldade visual em 17, deficits auditivos em 14, alterações da fala em 10, alterações sensitivas em 8, movimentos anormais em um e crises convulsivas em mais de $50 \%$ dos casos. Thompson, Kötter, Meyer, citados 
por Madonick e col. ${ }^{4}$, relatam grande incidência de hidrocefalia em pacientes com cisto e cavo do septo pelúcido.

Nossos casos corroboram a asserção de que a agenesia do septo pelúcido não é associada com um quadro clínico definido ou com sintomas particulares. A diferenciação entre agenesia e cavo do septo pelúcido não pode ser feita pelos sinais ou sintomas apresentados pelo paciente, porque os achados clínicos são semelhantes.

A ocorrência de agenesia do septo pelúcido sem outra malformação associada é bastante rara.

\section{R E S U M O}

São apresentados 4 casos de agenesia e um de cavo do septo pelúcido. São feitos comentários sôbre a incidência, sintomatologia e associações com outras anomalias, chamando a atenção para a inexistência de um quadro clínico próprio ou de um sintoma peculiar nestas duas entidades.

\section{S U M M A R Y}

Agenesis and cavum of septum pellucidum: report of five cases

Four cases of agenesis and one of cavum of septum pellucidum are reported. Comments on the incidence, symptomatology and association with other anomalies, emphasizing the absence of a definite clinical picture or symptom are made.

\section{R E F E R E N C I A S}

1. DYKE, C. G. \& DAVIDOFF, L. M. - Congenital absence of septum pellucidum: its diagnosis by encephalography. Am. J. Roentgenol. 34:573, 1935.

2. HUGHES, R. A.; KERNOHAN, J. W. \& CRAIG, W. M. - Caves and cysts of septum pellucidum. Am. J. Roentgenol. 59:17, 1948.

3. LOWMÁN, R. M.; SHAPIRO, R. \& COLLINS, L. C. - Significance of widened septum pellucidum. Am. J. Roentgenol. 59:117, 1948.

4. MADONICK, M. J.; GILBERT, S. \& STERN, W. Z. - Partial agenesis of septum pellucidum with cave of septum pellucidum: report of a case with review of literature. Arch. Neurol. (Chicago) 11:324, 1964.

5. SCHUNK, H. - Congenital dilatations of septum pellucidum. Radiology 81:610, 1963.

6. SCHWIDDE, J. T. - Incidence of cavum septi pellucidi and cavum vergae in 1.032 human brains. Arch Neurol. Psychiat. (Chicago) 67:625, 1952.

7. ST. JOHN, J. R. \& REEVES, D. L. - Congenital absence of the septum pellucidum: a review of the literature with case report. Amer. J. Surg. 94:974, 1957.

8. THIEFFRY, S.; LEFEBVRE, J.; LEPINTRE, J.; FAURE, C. \& MASSELIN, S. - Contribution à l'étude radiologique des malformations du plan sagittal interhemispherique à propos de 45 observations. Acta radiol. (Stockholm) 50:242, 1958.

9. ZELLWEGER, H. \& Von MURALT, G. - Zur Pathologie das Septum Pellucidum im Pneumoencephalogramm. Helvet. paediat. Acta 7:229, 1952. 